\title{
CONCEPÇÕES DE FUTUROS PROFESSORES SOBRE ÁGUAS SUBTERRÂNEAS
}

\section{FUTURE SCIENCE EDUCATOR'S CONCEPTIONS ABOUT GROUND WATER}

\author{
Claudia de Vilhena Schayer Sabino* \\ Wolney Lobato** \\ Francisco Ângelo Coutinho ${ }^{* * *}$ \\ Ana Caroline Zampiroli Ataide \\ Amaury Pires Bueno ${ }^{* * * *}$
}

\begin{abstract}
Resumo
Águas subterrâneas são fonte de água potável para muitas pessoas em todo o mundo, principalmente em áreas rurais. Por este motivo a qualidade destas águas é de importância fundamental. Inúmeros materiais tem sido identificados como contaminantes de águas subterrâneas. Apesar de ser este um precioso recurso natural, poucos professores tem conhecimento suficiente sobre o tema, compreendendo os diferentes conceitos envolvidos. Este estudo teve como objetivo avaliar as percepções e o conhecimento sobre o assunto de futuros professores de ciências. 100 estudantes de licenciatura participaram da pesquisa e os resultados indicam que os participantes tem concepções insuficientes sobre os princípios de hidrologia, apesar da importância das águas subterrâneas para a saúde, economia e qualidade de visa. Ficou demonstrada a importância de melhorar o conhecimento de alunos e professores sobre conceitos relacionados a este tema.
\end{abstract}

Palavras-chave: Águas subterrâneas, fontes de contaminação, ensino.

\begin{abstract}
Ground water is the source of drinking water for many people around the world, many people, the quality of ground water is of Paramount importance. A wide variety of materials have been identified as contaminants found in groundwater. Although clean, potable groundwater constitutes one of our most valuable resources, few concept. In this study the knowledge and perceptions about groundwater of future science educator were assessed and data were collected from 100 science students. The results of this study indicate that the participants held inappropriate conceptions of hydrogeologic principles despite groundwater's importance to their health and water among science students and teachers.

\footnotetext{
* Mestrado Profissional em Ensino - PUC Minas. E-mail: sabinoc@pucminas.br

** Coordenador de Pesquisa - PUC Minas. E-mail: proppg@pucminas.br

*** Mestrado Profissional em Ensino - PUC Minas. E-mail: fac01@terra.com.br

${ }^{* * * *}$ Curso de Ciências Biológicas - PUC Minas. E-mail: anacaroline88@ig.com.br

${ }^{* * * * *}$ Curso de Ciências Biológicas - PUC Minas. E-mail:

riuama_onube@yahoo.com.br
} especially in rural areas. Inasmuch as ground water provides drinking water to so science educators hold complete and appropriate understandings regarding the economic well-being. It is important to improve conceptual understanding of ground 


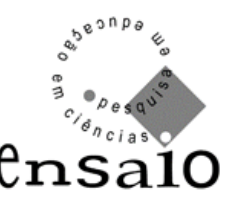

Keywords: Groundwater, contamination sources, class activity.

\section{INTRODUÇÃO}

Águas subterrâneas são fontes de água potável para muitas pessoas no mundo, principalmente em áreas rurais, além de utilizadas em abastecimento, irrigação, indústrias, minerações e geração de energia geotérmica.

Uma grande variedade de substâncias tem sido encontrada como contaminadores de águas subterrâneas: materiais orgânicos, inorgânicos e radioativos, além de bactérias e vírus (ALLEN, 1993; FETTER, 1992, KUCHLER, 2000). Estes contaminadores geralmente estão localizados no solo e/ou rocha, que possuem grande capacidade de retenção de substâncias (SABINO, 1998). Quando esta capacidade é ultrapassada, poluentes ficam à disposição de águas que se infiltram, podendo após algum tempo atingir os depósitos de águas subterrâneas (ROMERO, 1991). Uma vez contaminado, o depósito de águas subterrâneas pode tornar-se impróprio para qualquer uso. Considerando que esses depósitos são reservas de água, sua proteção é de vital importância. Por este e outros motivos é importante a conscientização de todos sobre a importância deste precioso recurso natural, pois sem efetivas mudanças comportamentais da sociedade e sem a aplicação concreta da legislação e diretrizes de proteção ambiental, dentro de poucas décadas estaremos sujeitos a um verdadeiro colapso da disponibilidade de água, o que poderá colocar em perigo a sobrevivência da humanidade (MINISTÉRIO DA AGRICULTURA PECUÁRIA E ABASTECIMENTO, 2002) .

O primeiro uso de água subterrânea como fonte para suprimento de água está na Antigüidade, mas durante séculos, esse uso foi limitado por dificuldades técnicas e o não conhecimento claro da origem e ocorrência dessas águas. A introdução de máquinas perfuratrizes e bombas motorizadas tornaram possível a utilização de águas subterrâneas em grande quantidade e em maiores profundidades. O uso dessas águas para finalidades domésticas (consumo humano e animal) tem normalmente a maior prioridade, seguida da utilização industrial e do uso na agricultura (irrigação); tendo crescido cada vez mais principalmente em locais nos quais a possibilidades de utilização das águas superficiais já foram esgotadas ou são inexistentes (STANIMIROVA, 2005). O uso real não segue esta prioridade natural, pois 69\% são 


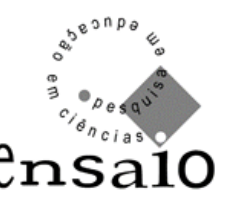

utilizadas na agricultura, 23\% na indústria e apenas 8\% são para uso doméstico (FETTER, 1992).

No Brasil, 15,6 \% dos domicílios utilizam exclusivamente água subterrânea, 77,8 \% usam rede de abastecimento de água e 6,6 \% usam outras formas de abastecimento (IBGE, 2002). É importante destacar que, entre os domicílios que possuem rede de abastecimento de água, uma parte significativa usa água subterrânea, que desempenha importante papel no desenvolvimento socioeconômico do país (ANA, 2005).

Mesmo em regiões onde há suprimento de água, fontes naturais subterrâneas, obtidas em cisternas e poços tubulares, são utilizadas pela população de baixa renda, devido à economia que a alternativa proporciona, eximindo o usuário do pagamento da conta de consumo de água. Além do mais, esses meios representam fonte segura e adicional no suprimento de água em áreas onde muitas vezes o fornecimento não é regular (NASCIMENTO, 2005).

Para exemplificar, no Estado de São Paulo, dos 645 municípios, 462 (71,6\%) são abastecidos total ou parcialmente com águas subterrâneas, sendo que 308 (47,7\%) são municípios totalmente abastecidos por este recurso hídrico. Nesse Estado, cerca de 5.500.000 pessoas são abastecidas diariamente por águas subterrâneas (SILVA, 2002). No Maranhão, mais de 70 \% das cidades usam água de poços, e no Estado do Piauí este percentual supera $80 \%$.

É então, importante a abordagem do assunto no ensino de ciências, por se enquadrar no tema meio ambiente, que de acordo com os PCN's, entre outros objetivos visa levar o aluno a:

Compreender que os problemas ambientais interferem na qualidade de vida das pessoas, tanto local quanto globalmente; conhecer e compreender, de modo integrado, as noções básicas relacionadas ao meio ambiente; perceber, em diversos fenômenos naturais, encadeamentos e relações de causa/efeito que condicionam a vida no espaço (geográfico) e no tempo (histórico), utilizando essa percepção para posicionar-se criticamente diante das condições ambientais de seu meio; compreender a necessidade e dominar alguns procedimentos de conservação e manejo dos recursos naturais com os quais interagem, aplicando-os no dia-a-dia. (BRASIL, 1998)

Também o Ministério do Meio Ambiente no Programa Nacional de Águas Subterrâneas - PNAS considera que: 
a ampliação do conhecimento hidrogeológico é a primeira etapa para subsidiar a implantação de um sistema de gestão realmente integrado entre as águas subterrâneas e as superficiais, já que atualmente a gestão é focada no componente das águas superficiais, pelo fato desta ter maiores visibilidade e disponibilidade de dados e estudos. (MINISTÉRIO DO MEIO AMBIENTE, 2009)

Diversos alunos e professores apresentam dificuldades em entender aspectos relacionados a essas águas. As dificuldades têm sido pesquisadas e encontradas em diversos outros países (DICKERSON, 2004; 2005; 2007; SUVERDI, 2000).

Este trabalho tem como objetivo analisar o conhecimento de futuros professores sobre o tema com a finalidade de propor uma abordagem mais ampla do mesmo, nos diferentes níveis de ensino.

\section{METODOLOGIA}

Cem (100) questionários sobre o tema foram aplicados a alunos de cursos de licenciatura e pedagogia. Esta estratégia metodológica baseia-se no fato de que a identificação de concepções dos futuros professores é um importante passo em direção ao ensino e a aprendizagem de ciências, pois muitas concepções errôneas ou incompletas são propagadas por professores (YIP, 1998). Segundo Pinto (2007), a falta de uma política governamental destinada à alfabetização científica , a ausência de material didático adequado e de qualidade, em especial o livro texto, e a má formação dos profissionais de ensino são causas para a baixa qualidade do ensino de Ciências.

Os questionários foram aplicados a alunos do quarto e quinto semestre de licenciaturas em Ciências Biológicas, Física e Pedagogia da Pontifícia Universidade Católica de Minas Gerais, durante 2007 e 2008. A amostragem foi feita pela técnica de comodidade: estes são os cursos de licenciatura nos quais os autores lecionam.

O questionário aplicado foi composto de questões abertas e fechadas. Foi feita adaptação no questionário sugerido por Dickerson (2007) (Anexo 1).

A solicitação de que os alunos produzissem uma ilustração baseia-se no fato de desenhos serem importantes componentes do discurso científico. Aprender tópicos científicos implica saber ler, entender e comunicar-se tanto oralmente, quanto por meio da escrita na linguagem específica das áreas (BARAM, 2004). Assim, partimos da hipótese de que um desenho poderia revelar o entendimento dos alunos sobre o tema em questão. 


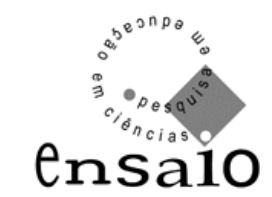

As questões fechadas foram tabuladas conforme procedimento habitual de contagem de freqüência. Já as questões abertas, exigiram a leitura atenta no sentido de categorizar temas comuns, considerando como mais relevantes aqueles citados com maior freqüência. Assim por exemplo, na questão sobre onde o respondente “aprendeu sobre águas subterrâneas” várias categorias foram estabelecidas.

\section{RESULTADOS E DISCUSSÃO}

A primeira questão do questionário consistiu em solicitar aos respondentes que desenhassem o ciclo da água. Algumas vezes o desenho demonstra mais apropriadamente a visualização mental dos estudantes sobre um fenômeno natural (DICKERSON, 2007). Um exemplo dos desenhos obtidos está apresentado na Figura 1. Os resultados foram categorizados conforme está apresentado no Quadro 1.

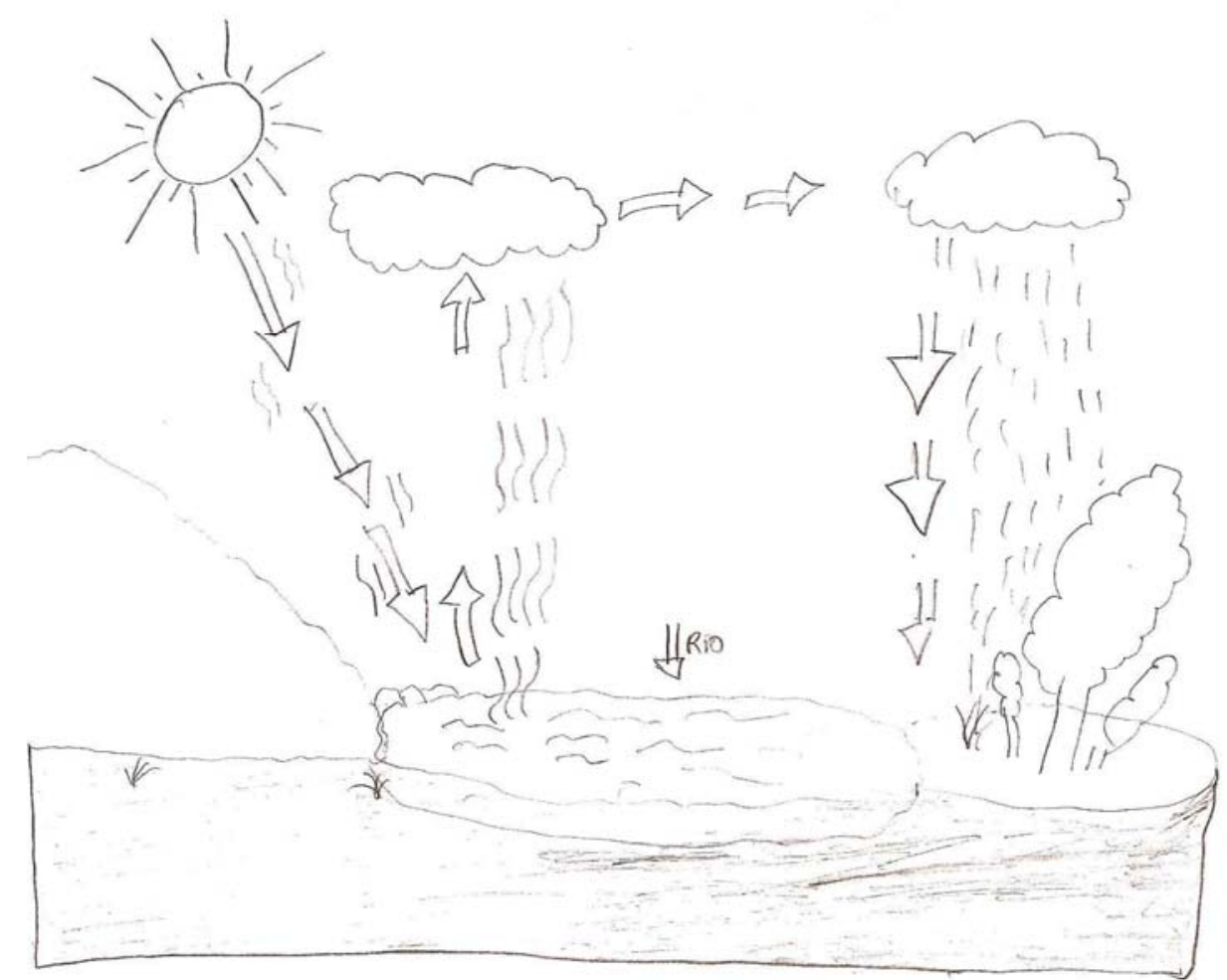

Figura 1 - Desenho do ciclo da água elaborado por um aluno de licenciatura em Ciências Biológicas.

\begin{tabular}{|c|c|c|}
\hline Categoria & Etapa & $\%$ \\
\hline 1 & Condensação e precipitação & 43 \\
\hline 2 & Enxurrada & 2 \\
\hline 3 & Evaporação & 37 \\
\hline
\end{tabular}




\begin{tabular}{|c|c|c|}
4 & Respiração e evapotranspiração & 11 \\
\hline 5 & Infiltração & 13 \\
\hline
\end{tabular}

\section{Quadro 1 - Resultado da categorização das etapas do ciclo da água} representadas nos desenhos dos respondentes ao questionário

A grande maioria dos alunos não desenhou o ciclo da água completo. Etapas muito importantes, como a enxurrada e a infiltração foram pouco representadas. Resultados semelhantes são encontrados na literatura (SUVEDI, 2000), o que demonstra a necessidade de discussões mais detalhadas sobre o ciclo da água nos diferentes níveis do ensino. É importante que os professores saibam que as águas subterrâneas são parte integrante do ciclo da água e que o ciclo continua mesmo onde os olhos não podem alcançar (DICKERSON, 2007).

A segunda questão foi relacionada à ocorrência das águas subterrâneas: "Se uma pessoa procurar águas subterrâneas, em quais locais ela provavelmente encontrará?” As respostas estão apresentadas no Quadro 2.

\begin{tabular}{|c|c|}
\hline Local & $\%$ \\
\hline a. Rio subterrâneo & 14 \\
\hline b. Camada de areia & 2 \\
\hline C. Poço & 13 \\
\hline d. Reservatório subterrâneo & 13 \\
\hline e. Solo & 11 \\
\hline f. Cisterna & 12 \\
\hline g. Rochas fraturadas & 6 \\
\hline h. Canais escoamento & 4 \\
\hline i. $\quad$ Lago subterrâneo & 12 \\
\hline j. Fornecimento da cidade & 2 \\
\hline k. Cavernas & 10 \\
\hline
\end{tabular}

Quadro 2 - Resultado da questão relativa aos locais onde ocorrem as águas subterrâneas

A marcação das letras "b”, “g” e/ou “e” indicam um conhecimento correto sobre a ocorrência de águas subterrâneas. Já a marcação destas letras conjuntamente com uma ou ambas as letras c e h indicam que o aluno sabe que a água subterrânea ocorre abaixo da superfície da terra, mas não entende como funciona. Qualquer marcação além das mencionadas indica desconhecimento do tema (DICKERSON, 2004). 
De acordo com as repostas a maioria dos alunos não compreende a localização das águas subterrâneas. Não sabem que os aqüíferos porosos ocorrem em rochas sedimentares consolidadas, sedimentos inconsolidados e solos arenosos, decompostos “in situ”. Constituem os mais importantes aqüíferos, pelo grande volume de água que armazenam, e por sua ocorrência em grandes áreas. Estes aqüíferos ocorrem nas bacias sedimentares e em todas as várzeas onde se acumularam sedimentos arenosos. De forma geral, os terrenos sedimentares apresentam os melhores aqüíferos, e ocupam cerca de $4.130 .000 \mathrm{~km}^{2}$, ou seja, aproximadamente 48\% do território nacional (ANA, 2005).

Os aqüíferos fraturados ou fissurados ocorrem em rochas ígneas e metamórficas. A capacidade destas rochas em acumularem água está relacionada à quantidade de fraturas, suas aberturas e intercomunicação. No Brasil a importância destes aqüíferos está muito mais em sua localização geográfica, do que na quantidade de água que armazenam.

Os aqüíferos cársticos são os formados em rochas carbonáticas. São comuns em regiões com grutas calcárias, ocorrendo em várias partes do Brasil. Os aqüíferos cárstico-fraturados e fraturados, que ocupam cerca de $4.380 .000 \mathrm{~km}^{2}, 52 \%$ do território nacional. (ANA, 2005). O conhecimento dos tipos de aqüíferos está relacionado ao da ocorrência sendo importante para a sua proteção. Os alunos (futuros professores) desconhecem estes fatos.

Águas subterrâneas não são estudadas detalhadamente nos cursos de licenciatura apesar da importância no passado, no presente e no futuro.

A terceira questão foi relacionada à origem e movimento das águas subterrâneas: "Desenhe como as águas subterrâneas ocorrem e como elas se movem no esquema abaixo.” O desenho não é necessariamente uma réplica exata do modelo mental do estudante, mas apresenta informações espaciais sobre os fenômenos naturais. O esquema apresentado no questionário é o sugerido por Dickerson (2006) e está anexado. 44\% dos respondentes desenharam rios subterrâneos, outros 44\% representaram em seus desenhos a infiltração da água e 12\% desenhou um depósito subterrâneo de água, sobre rochas.

Apenas $12 \%$ dos respondentes demonstraram ter algum conhecimento sobre a ocorrência e o movimento de águas subterrâneas, o que é indispensável para a proteção destas águas. O conceito popular e errôneo de rio subterrâneo foi largamente 
representado, conforme citado na literatura (DICKERSON, 2004; 2005; 2007; SUVERDI, 2000). Alguns conceitos populares sobre águas subterrâneas são ingênuos e cientificamente incorretos, sendo importante que os professores forneçam aos alunos informações corretas, indispensáveis para a formação crítica do cidadão (LEGARE, 2009). O resultado desta questão sugere a necessidade de melhor visualização dos fenômenos relacionados à água subterrânea através de abordagem mais detalhada do tema nas escolas, incluindo a utilização de modelos físicos, programas de computador e visitas técnicas.

A quarta questão foi sobre a ocorrência de águas subterrâneas no Brasil: Descreva o que você sabe sobre a existência de águas subterrâneas no Brasil. 55\% dos respondentes declararam não ter conhecimento do assunto, 14\% declararam conhecer a existência do Aqüífero Guarani, 25\% afirmaram que as águas subterrâneas ocorrem em grande escala e $6 \%$ em pequena escala.

No Brasil as reservas de águas subterrâneas são estimadas em 112 trilhões de $\mathrm{m}^{3}$. Estão distribuídas em praticamente todo o país sendo largamente utilizada por meio de cisternas e poços artesianos. Importantes cidades do país dependem integral ou parcialmente da água subterrânea para abastecimento, como, por exemplo: Ribeirão Preto (SP), Mossoró e Natal (RN), Maceió (AL), Região Metropolitana de Recife (PE) e Barreiras (BA). As águas subterrâneas termais estimulam o turismo em cidades como Caldas Novas em Goiás, Araxá e Poços de Caldas em Minas Gerais (ABAS, 2009). A maioria dos respondentes não conhece estes fatos.

A quinta pergunta foi relacionada à extensão dos depósitos de águas subterrâneas: Imaginando onde as águas subterrâneas ocorrem qual a extensão que você imagina que elas ocupam? A) Alguns metros; B) Alguns quilômetros; C) Milhares de quilômetros.

Obtivemos que $48 \%$ marcaram a resposta A, 33\% marcaram a B e apenas $19 \%$ marcaram a letra $\mathrm{C}$, o que está de acordo com a resposta da questão anterior na qual 14\% declararam ter conhecimento sobre o Aqüífero Guarani, que freqüentemente é citado na mídia.

Muitos alunos associam as águas subterrâneas às cisternas, que são largamente utilizadas no Brasil, imaginando que estas se restringem aos poços rasos utilizados principalmente em áreas rurais. 
A sexta questão se referiu ao local no qual o respondente aprendeu sobre águas subterrâneas. O resultado categorizado está apresentado no Quadro 3.

\begin{tabular}{|c|c|}
\hline Categoria & $\%$ \\
\hline Não me lembro & 6 \\
\hline Escola & 41 \\
\hline Cursinho pré-vestibular & 1 \\
\hline Universidade & 9 \\
\hline Mídia eletrônica & 14 \\
\hline Mídia impressa & 23 \\
\hline Conhecimento popular & 5 \\
\hline
\end{tabular}

Quadro 3 - Resultado da questão relativa ao local no qual o respondente obteve conhecimentos sobre águas subterrâneas.

Os resultados demonstram que apesar do desenvolvimento de mídias, principalmente eletrônicas, a escola continua a ser a principal fonte de conhecimentos para os estudantes (futuros professores).

A sétima questão se referiu aos usos da água subterrânea. Os resultados categorizados estão apresentados no Quadro 4. Novamente as respostas apresentam os conhecimentos populares que nem sempre estão de acordo com a realidade. As pessoas acreditam que a maior parte das águas subterrâneas é utilizada para abastecimento quando na realidade o principal uso é a agricultura. Não existe no Brasil um levantamento geral sobre a distribuição do uso das águas subterrâneas. Por exemplo, o da Província Escudo Setentrional é caracterizado pela ausência quase total de informações hidrogeológicas e inclui os aqüíferos Boa Vista, Tacatu, e Grupo Roraima e Beneficente (MINISTÉRIO DO MEIO AMBIENTE, 2007).

\begin{tabular}{|c|c|}
\hline Categoria & $\%$ \\
\hline Não sei & 20 \\
\hline Agricultura & 25 \\
\hline Indústria & 9 \\
\hline Abastecimento & 44 \\
\hline Mineração & 2 \\
\hline
\end{tabular}

Quadro 4 - Resultado da questão relativa aos usos das águas subterrâneas.

A oitava questão foi sobre fontes de contaminação: “Cite quais são as principais fontes de contaminação de águas subterrâneas.”. Os resultados categorizados estão apresentados no Quadro 5. 


\begin{tabular}{|c|c|}
\hline Categoria & $\%$ \\
\hline Não sei & 8 \\
\hline Chorume & 31 \\
\hline Esgoto & 22 \\
\hline Agropecuária & 24 \\
\hline Combustíveis & 2 \\
\hline Mineração & 5 \\
\hline Indústria & 8 \\
\hline
\end{tabular}

ensa10

\section{Quadro 5 - Resultado da questão relativa às fontes de contaminação das águas subterrâneas.}

As duas principais fontes de contaminação de águas subterrâneas, esgotos e agropecuária foram mencionadas, mas outras fontes importantes, como escoamento urbano ou poluentes atmosféricos não foram mencionados.

O esgoto ter sido lembrado por parte dos alunos é importante, pois no Brasil, o índice médio de domicílios com esgotamento sanitário é de apenas 50,6\%. Em relação ao tratamento dos esgotos, os resultados são ainda mais preocupantes, pois o índice nacional médio de tratamento dos esgotos gerados na área urbana é de apenas 28,2\% (IBGE, 2009). Este quadro deficitário gera impacto não apenas sobre os rios, mas influi diretamente sobre a qualidade da água subterrânea, especialmente nas áreas urbanas (NUISSL, 2009). A falta de saneamento representa um risco às águas subterrâneas através da infiltração por fossas negras do escoamento superficial, que acaba infiltrando no solo, e pelo vazamento de redes de esgoto. Este quadro é especialmente crítico nas cidades em que existe uma elevada densidade populacional e, portanto, alta taxa de produção de esgotos (ANA, 2005).

A agricultura também representa em todo o mundo uma importante fonte de contaminação de águas subterrâneas. A irrigação geralmente lança no solo uma quantidade de água maior do que a necessária para a evaporação e transpiração. Este excesso de água carreia materiais diversos do solo até os lençóis freáticos. Entre estes materiais estão os produtos utilizados na agricultura como fertilizantes e pesticidas. Há então um conseqüente aumento da salinidade e contaminação do solo e da água.

Também é fonte de contaminação a aplicação de pesticidas, os produtos químicos que são aplicados para controle de pragas, assim como no controle do crescimento e otimização nas plantações. O uso destes produtos implica em risco de contaminação do ambiente e das águas subterrâneas através da migração. Mesmo 
produtos biodegradáveis produzem metabólitos tóxicos, que são encontrados em aqüíferos freáticos.

Além disto, a aplicação de fertilizantes que contem basicamente fósforo, potássio e nitrogênio implica em mais um risco. Fertilizantes à base de nitratos são essenciais à agricultura, mas podem contaminar águas subterrâneas (NETO, 1997).

A agropecuária é também importante fonte de contaminação. Animais confinados podem causar contaminação devida à lixiviação do rejeito produzido. Muitos fazendeiros utilizam este rejeito para adubo, entretanto não são tomados os cuidados necessários para a estocagem e utilização, havendo o risco dos contaminadores atingirem o ambiente e conseqüentemente as águas subterrâneas.

O escoamento superficial urbano pode gerar contaminação, pois nos grandes centros urbanos o lixo, os esgotos e a água encanada, podem atingir aqüíferos. Diversas atividades desenvolvidas nas cidades contaminam reservas de águas subterrâneas, tanto no Brasil quanto no resto do mundo (ALMASRI, 2007; CAMPONOGARA, 2004; NOBREGA, 2006; OLIVEIRA, 2005; ROCHA, 2006; ROSA FILHO, 2002).

Também, a contaminação de águas subterrâneas por vazamentos em postos de combustíveis vem merecendo cada vez mais atenção tanto da população em geral como dos órgãos estaduais de controle ambiental (CORSEUIL, 1997). Uma das principais fontes de contaminação são os vazamentos de combustíveis dos postos de distribuição em função do envelhecimento dos taques de estocagem. A contaminação por gasolina está relacionada com hidrocarbonetos aromáticos, dentre os quais se destacam benzeno, tolueno e xilenos (BRITO, 2005).

Os poluentes atmosféricos atingem o solo através de deposição ou precipitação. Entre estes estão os resíduos de descarga de veículos, gases industriais e os provenientes de incineradores. Entre os poluentes destacam-se hidrocarbonetos, produtos químicos sintéticos e naturais, metais pesados e compostos de nitrogênio e enxofre. Uma vez que atingirem o solo os poluentes podem alcançar os aqüíferos tornando inviável a utilização das águas.

A nona questão foi sobre a necessidade de conservar águas subterrâneas: "É importante conservar as águas subterrâneas? Você concorda? Explique.” Quase a metade dos respondentes (48\%) afirma não saber para que conservar águas subterrâneas. 52\% concordam ser importante conservar águas subterrâneas. 25\% 
concordam porque são reservas de água, 23\% são suprimentos de água e 3\% porque são importantes na manutenção do ciclo da água.

\section{CONCLUSÕES}

Os fenômenos de transporte de contaminadores em zona de vadosa (região do solo entre a superfície e o aqüífero) podem ser extremamente lentos. Um contaminador lançado na superfície da terra pode demorar até 100 anos para atingir aqüíferos (SABINO, 1998). As ações atuais, como sempre, irão interferir na qualidade de vida das gerações futuras. A proteção dos aqüíferos é de fundamental importância atual e futura. Como só se protege o que se conhece, é fundamental a conscientização de todos sobre a importância deste precioso recurso natural, pois um aqüífero uma vez contaminado pode se tornar impróprio para o uso.

Os resultados indicam que os futuros professores que participaram da pesquisa não possuem conhecimento suficiente sobre a ocorrência, movimento, uso e contaminação de águas subterrâneas. Essa falta de conhecimento foi detectada em aspectos simples como o ciclo da água. É importante que os professores saibam que a água subterrânea é parte integrante deste ciclo, que continua mesmo em locais que os olhos não podem alcançar.

Os resultados indicam também que não é conhecida a importância da proteção deste valioso recurso natural. Estes fatos estão de acordo com os encontrados na literatura internacional. Em diversos países estudos semelhantes ao aqui descritos constataram que adultos, jovens e crianças desconhecem os conceitos e a problemática relacionada à águas subterrâneas.

Embora o uso seja extenso e crescente, a preocupação a respeito da poluição das águas subterrâneas é relativamente recente no nosso país, uma vez que o usuário do recurso subterrâneo, particular ou governamental, até pelo menos a década de 90, desconhecia e ignorava a sua importância e as graves conseqüências de sua contaminação.

Os estudos referentes aos recursos hídricos subterrâneos são fundamentais e necessitam de maior atenção, também com vistas a evitar futuras situações de degradação deste recurso. O conhecimento que desenvolvemos hoje irá impactar a 


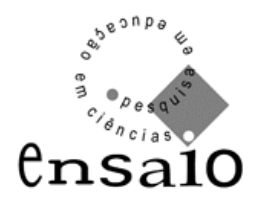

qualidade de decisões futuras, sendo necessário que o tema seja mais abordado nos cursos de formação de professores.

\section{AGRADECIMENTOS}

Agradecemos ao Fundo de Incentivo a Pesquisa (FIP) da PUC Minas e à FAPEMIG pelo financiamento desta pesquisa e pela concessão de bolsas de iniciação científica.

\section{REFERÊNCIAS BIBLIOGRÁFICAS}

ALLEN, H. E.; PERDUE, E. M; BROWN, D. S. Metals in groundwater. Lewis: Chelsea, 1993. p.193.

ANA - Agência Nacional das Águas - Cadernos de Recursos Hídricos - Panorama da qualidade das águas subterrâneas do Brasil. Superintendência de Planejamento de Recursos Hídricos Superintendência de Conservação de Água e Solo. Brasília, DF. Maio, 2005.

ALMASRI, M. N. Nitrate contamination of groundwater: A conceptual management framework. Environmental Impact Assessment Review, v.27, p.220-242, 2007.

ASSOCIAÇÃO BRASILEIRA DE ÁGUAS SUBTERRÂNEAS (ABAS). Águas subterrâneas o que são. Disponível em: http://www.abas.org/educacao.php\#ind24 . Acesso em: fevereiro 2009.

BARAM-TSABARI, A.; YARDEN, A. Text Genre as a Factor in the Formation of Scientific Literacy. Journal of Research in Science Teaching, Maryland, v.42, Issue 4, p.403-428, 2005.

BRASIL. SECRETARIA DE EDUCAÇÃO FUNDAMENTAL. Parâmetros curriculares nacionais: terceiro e quarto ciclos do ensino fundamental: introdução aos parâmetros curriculares nacionais. Brasília: SEF, 1998.

BRITO, F. V. et al. Estudo da Contaminação de Águas Subterrâneas por BTEX oriundas de postos de distribuição no Brasil. In: $3^{\circ}$ Congresso Brasileiro de P\&D em Petróleo e Gás. 2 a 5 de outubro de 2005, Salvador. Anais.... Salvador. 2005.

CAMPONOGARA I. et al. Mapeamento da Vulnerabilidade Natural à Contaminação de Aqüíferos e Risco de Poluição dos Recursos Hídricos Subterrâneos no Município de Soledade/RS. In: COBRAC 2004 - Congresso Brasileiro de Cadastro Técnico Multifinalitário. UFSC. Florianópolis. 10 a 14 de Outubro 2004. Anais... Florianópolis: UFSC. 2004. 


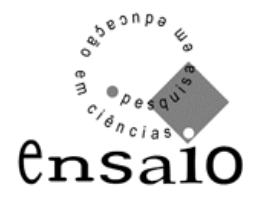

CORSEUIL H. X.; MARINS M.; DAL, M. Contaminação de águas subterrâneas por derramamentos de gasolina: o problema é grave? Revista Engenharia Sanitária e Ambiental, v.2, n.2, p.50-54, 1997.

DICKERSON D.; DAWKINS, K. Eighth Grade Students' Understandings of Groundwater. Journal of Geoscience Education, v.52, n.2, Mar., p.178-181, 2004.

DICKERSON D. et al. Students' Conceptions of Scale Regarding Groundwater. Journal of Geoscience Education, v.53, n.4, September, p.374-380, 2005.

DICKERSON, D. L.; PENICK, J. E.; DAWKINS, K. R.; SICKLE, M. Van. Groundwater in Science Education. Journal of Science Teacher Education. v.18, p.45-61, 2007.

FETTER, C. W. Contaminant hydrogeology. New York: Macmillan, 1992. p.458.

INSTITUTO BRASILEIRO DE GEOGRAFIA E ESTATÍSTICA (IBGE). Pesquisa Nacional por Amostra de Domicílios - 2002. Rio de Janeiro: IBGE, 2002b. CDROM.

INSTITUTO BRASILEIRO DE GEOGRAFIA E ESTATÍSTICA (IBGE). Indicadores de desenvolvimento sustentável. Disponível em: http://www.ibge.gov.br/servidor_arquivos_est/ . Acesso em fevereiro de 2009.

KUCHLER, I. L.; MIEKELEY, N.; FORSBERBG, B. R. A contribution to the chemical characterization of rivers in the Rio Negro Basin, Brazil. J. Braz. Chem. Soc. May/June. v.11. n.3. p.286-292. 2000.

MINISTÉRIO DA AGRICULTURA PECUÁRIA E ABASTECIMENTO. Agricultura e qualidade das águas: contaminação pelo nitrato. EMBRAPA. Planaltina. DF. 2002.

NASCIMENTO, S. A. M.; BARBOSA, J. S. F. Qualidade da água do aqüífero freático no alto cristalino de Salvador, bacia do rio Lucaia, Salvador, Bahia. Revista Brasileira de Geociências. v.35, n.4, p.543-550, 2005.

NETO, R. B. Bactérias do inferno, Folha de São Paulo, São Paulo, p.5-16, 9 de nov., 1997.

MINISTÉRIO DO MEIO AMBIENTE. O Programa Nacional de Águas Subterrâneas - PNAS - Versão Preliminar. Disponível em: http://www.mma.gov.br/sitio/index.php?ido=conteudo.monta\&idEstrutura=167.

Acesso em fevereiro de 2009.

NÓBREGA M. M. S.; SANTOS, J. P.; ARAÚJO, A. L. C.. Qualidade das águas subterrâneas na grande Natal: o alcance da contaminação por nitrato nas águas minerais. In: I Congresso de Pesquisa e Inovação da Rede Norte Nordeste de Educação Tecnológica. Natal. 2006. Anais... Natal. 2006. 
MINISTÉRIO DO MEIO AMBIENTE. Águas subterrâneas: um recurso a ser conhecido e protegido. Brasília: MINISTÉRIO DO MEIO AMBIENTE. 2007. Disponível em: http://www.mma.gov.br/sitio/index.php?ido=conteudo.monta\&idEstrutura=167.

Último acesso em fevereiro de 2009.

NUISSL, H.. et al Environmental impact assessment of urban land use transitions - A context-sensitive approach. Land Use Policy. v.26, p.414-424. 2009.

OLIVEIRA, L. A. Vulnerabilidade do aqüífero livre no perímetro urbano de Rio Verde/GO: análise preliminar utilizando-se dados de espessura da zona vadosa. Caminhos de Geografia. v.5, n.14, p.54-61, Fev. 2005.

PINTO, S. P.; FONSECA O. M.; VIANNA D. M. Formação continuada de professores: estratégia para o ensino de astronomia nas séries iniciais. Cad. Brás. Ens. Fís. v.24, n.1, p.71-86, abril 2007.

RIBEIRO, M. L.; LOURENCETTI, C.; TEIXEIRA, D. Cenários de contaminação da água subterrânea por atividades agrícolas. Revista Uniara, n.17/18, 2005/2006.

ROCHA, L. C. R.; HORBE A. M. C. Contaminação provocada por um depósito de lixo no aqüífero Alter do Chão em Manaus - AM. Acta Amazônica. v.36, n.3, p.307312. 2006.

ROMERO, L.; MORENO, L.; NERETNIEKS, I. A compartment model for solute transport in the near field of a repository for radioactive waste. Stockholm: Department of Chemical Engineering, 1991, (KAT-91/13).

ROSA FILHO, E. F.; HINDI, E. C.; XAVIER, J. M.; LUCENA, L. R. F.; GUÉRÈQUIZ, A. DEL R.; Áreas de vulnerabilidade à contaminação de aqüífero cárstico causada pela explotação de poços tubulares (estudo de caso de ALMIRANTE TAMANDARÉ-PR, BRASIL). Revista Latino-Americana de Hidrogeologia, n.2, p.63-69, 2002.

SABINO, C. V. S. Sorção de nuclídeos no solo. 1998. Tese (Doutorado). Universidade Federal de Minas Gerais. Belo Horizonte. 1998.

SILVA, J. S. S. et al. Hipóteses sobre a origem do flúor no sistema aqüífero Guarani na Depressão Central gaúcha, Brasil. In: CONGRESSO BRASILEIRO DE ÁGUAS SUBTERRÂNEAS, 12, Florianópolis, 2002. Anais... Florianópolis: ABAS, 2002. CD-ROM.

SUVEDI, M. et al. Michigan Citizens' Knowledge and Perceptions About Groundwater. The Journal of Environmental Education. v.31, n.2, p.16-21, Wint, 2000.

YIP, D. Y. Identification of misconception in novice biology teachers and remedial strategies for improving biology learning. Int. J. Sci Educ., v.20, p.462-477, 1998. 


\section{ANEXO - Questionário Utilizado na Pesquisa}

\section{Curso:}

\section{Período:}

Questão 1: A água é indispensável à vida e se mantém ao longo do tempo no infinito ciclo da água. Faça um desenho que represente esse ciclo.

No questionário abaixo procure responder as perguntas sobre águas subterrâneas de acordo com o seu conhecimento sobre o assunto.

Questão 2: Se uma pessoa procurar águas subterrâneas, em quais locais ela provavelmente encontrará?
A) Rio subterrâneo
B) Camada de Areia
C) Poço
D) Reservatório de água subterrânea
E) Solo
F) Cisterna
G) Em rochas fraturadas
H) Em canais de escoamento
I) Lago subterrâneo
J) Em fornecimento de águas pelas cidades
K) Aqüíferos

Questão 3: Desenhe como as águas subterrâneas ocorrem e como elas se movem no esquema abaixo.

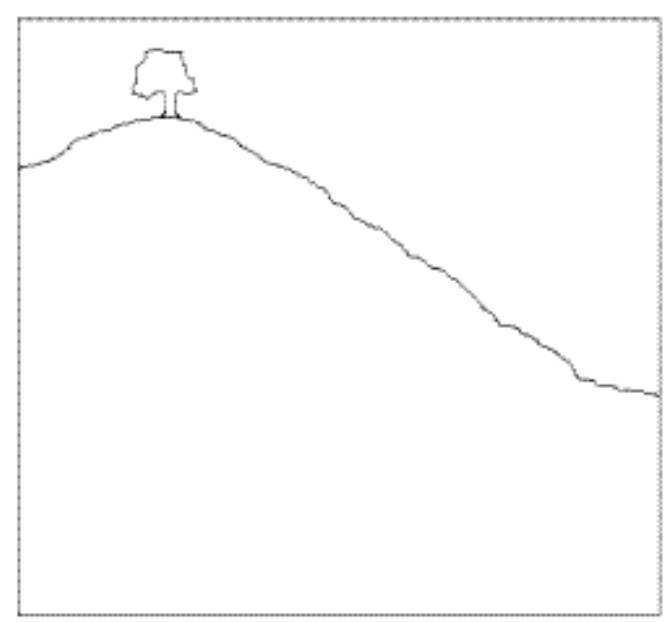

Questão 4: Descreva o que você sabe sobre a existência de águas subterrâneas no Brasil. 


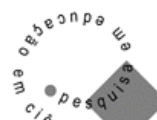 \\ ensa10}

Questão 5: Imaginando onde as águas subterrâneas ocorrem qual a extensão que você imagina que elas ocupam?
A) Alguns metros
B) Alguns quilômetros
C) Milhares de quilômetros

Questão 6: De onde vem seu conhecimento sobre águas subterrâneas?

Questão 7: Quais são os usos das águas subterrâneas?

Questão 8:Cite quais são as principais fontes de contaminação de águas subterrâneas.

Questão 9: É importante conservar as águas subterrâneas? Você concorda? Explique.

Data de recebimento: 06/03/09

Data de aprovação: 11/07/09

Data de versão final: 31/07/09 